is increased or diminished growth as compared with the active period of the day. This may explain the greater length of beard following a night of activity.

Hairs are cast at various intervals-from 18 months to six years-and are replaced by new hairs. A maximum length is peculiar to each hair, which grows back to just its original length after cutting. The rate of regrowth after cutting appears to vary with the age of the hair. A balance in the level of sebum on the skin surface is maintained in similar fashion, being restored rapidly after removal of surface grease. What exactly controls this natural maintenance of equilibrium is not known. It is, however, consistent with the knowledge that the stoutness and length of hair are not influenced by cutting and shaving, as is often feared by women suffering from hirsuties.

\section{Transplantation of Bone Marrow}

Q.-Has bone containing marrow ever been successfully transplanted from a healthy donor to a patient suffering from a marrow disorder, such as aplastic anaemia? A surgeon has raised the possibility of this treatment in cases of Cooley's anaemia.

A.- We have no record of this having been done, although there have been reports of unsuccessful attempts to transplant bone marrow. The basic difficulty in the failure to homograft tissues other than cornea and blood vessels is the development in the host of an actively acquired immunity against the particular tissue. Bone has been homografted in the past merely to serve as a strut and not to serve as a physiologically active unit. The technical problems involved in homografting bone containing bone marrow, with a view to red cell production, would be vast. For example, it would be necessary to ensure an adequate blood supply to the bone and its marrow. The problems would be even more complicated in Cooley's anaemia. In this anaemia, in addition to the basic familial defect, there is already hyperplasia of the bone marrow, and widespread structural changes in the bones, liver, and spleen. It is difficult to imagine a small amount of foreign bone marrow counteracting that clinical picture. In view of the familial defect in the red cell, homografting of bone marrow in an already enfeebled child would be a retrograde step from the experimental point of view.

\section{Causes of Gingivitis}

Q.-How should a case of gingivitis (no obvious pyorrhoea or caries) be investigated and treated?

A.- The causes of gingivitis are both local and general. Local causes include food stagnation, the wearing of dentures or appliances, rough or faulty fillings, lack of an adequately stimulating frictional diet, drying of the mucosa due to mouth-breathing, etc. General causes include disorders of the blood (e.g., leukaemias), vitamin deficiencies, deposition of heavy metals (e.g., mercury, bismuth), administration of certain drugs (e.g., phenytoin sodium), sometimes pregnancy. In many cases little obvious cause, save lack of adequate stimulation, can be found. Treatment will, of course, be founded on the diagnosis made.

\section{Buccal and Ano-genital Syndrome}

Q.-A married man of 38 , a clerk, has just had an attack of a burning sensation in the mouth with intense itching of the end of the penis and of the anus. In the mouth large snail-track ulcers appeared after 24-48 hours and healed in one week. No signs appeared in the anus, and the penis subsequently showed superficial ulceration, which may have been traumatic. He had a similar attack about two months ago, but has otherwise always been very healthy. Does this syndrome correspond to any clinical entity? What further investigations should be made? Can you suggest any prophylaxis or treatment?

A.- The signs and symptoms described could be a mild manifestation of the muco-cutaneous symptom complex that occurs with erythema multiforme. This skin disease may be associated with buccal, anal, conjunctival, penile, urethral, and vulvo-vaginal lesions, and cases have been recorded in which mucous membrane lesions have oscurred without involvement of the skin. With severe constitutional symptoms this type of disease is now known as StevensJohnson syndrome. Another closely allied syndrome (Behcet), in which involvement of the eyes is more severe, may be caused by the same infective agent. At present the cause of the disease is unknown: it may be due to a virus, especially as various workers have reported rapid cures with "aureomycin."

It is possible that the condition may be a drug eruption, and investigations should be carried out on these lines. Phenolphthalein, an ingredient of many proprietary laxatives, is frequently responsible. The two attacks in this patient were extremely mild, but, as with any ulceration on the genitalia, serological tests for syphilis should also be carried out.

\section{Squirting Cucumbers}

Q.-The fruit of the squirting cucumber (Ecballium elaterium) is used in Cyprus as a folk remedy for jaundice. It is put in the nose and inhaled. We have recently had a patient who not only inhaled the vapour but also ingested a certain amount of the juice. Within four days he had developed a severe multiple peripheral neuritis. He was not suffering from jaundice but had some nausea and epigastric discomfort, which he thought might be an early stage of hepatitis. I have been informed that the squirting cucumber does contain a toxic substance and that elaterium, which was included in the B.P.C. of 1934, was obtained from this source. I should be glad to know if any cases of peripheral neuritis have been reported following ingestion of the juice.

A.- There appear to be no references in the literature to the occurrence of peripheral neuritis following ingestion of the juice of the squirting cucumber. Elaterium is the dried sediment which deposits in the juice of the fruits of Ecballium elaterium. It is a powerful cathartic which is used in a dose up to $\frac{1}{2}$ gr. (32 mg.). It contains up to $30 \%$ of elaterin, which is the active ingredient and which is given in a dose up to $1 / 10 \mathrm{gr}$. $(6.5 \mathrm{mg}$.). The use of elaterin is frequently followed by prostration, according to Sollmann, and $10 \mathrm{gr}$. $(0.65 \mathrm{~g}$.) may be fatal. Goodman and Gilman also speak of elaterin as intensely irritating, and say that an overdose leads to severe prostration. There is, however, no mention of peripheral neuritis.

\section{Corrections}

The authors of the paper entitled "Some Observations on Endogenous Cortisone Excretion in Man " (Journal, September 29 , p. 762) wish to make acknowledgment to the Medical Research Council for a research grant given to Miss S. McCrae. They regret that through an oversight this acknowledgment was omitted from the original manuscript.

In the list of medical candidates who will be standing for Parliament at the General Election on October 25 (Journal, September 29, p. 793) we stated that Dr. Bernard Homa was honorary anaesthetist at the German Hospital, Dalston. Dr. Homa has told us that he no longer holds this appointment, but that he is a member of the London County Council, chairman of a divisional health committee, and a member of the board of governors of Charing Cross Hospital. During the last war he was a major in the R.A.M.C.

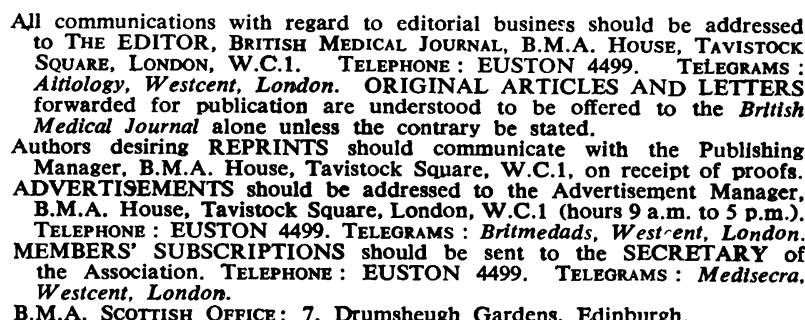

1l communications with regard to editorial business should be addressed to THE EDITOR, BrITISH MEDICAL JoURNAL, B.M.A. HouSE, TAVISTOCK SQUARE, LONDON, W.C.1. TELEPHONE: EUSTON 4499. TELEGRAMS : orwarded for publication are understood to be offered to the British Medical Journal alone unless the contrary be stated.

Manager. B.M R.PRINTS should communicate with the Publishing DVERTISEMENTS should be addressed to the Adve receipt of proofs. B.M.A. House, Tavistock Square, London, W.C.1 (hours 9 a.m. to 5 p.m.) MEMBERS' SUBSCRIPTIONS should be sent to the SECRETARY of Westcent, London.

B.M.A. Scortish OFFICE: 7, Drumsheugh Gardens, Edinburgh. 